\title{
Molecular Markers and Chemotherapy for Advanced Salivary Cancer
}

\author{
Vincent Vander Poorten · Jeroen Meulemans • \\ Pierre Delaere $\cdot$ Sandra Nuyts $\cdot$ Paul Clement
}

Published online: 28 January 2014

(c) Springer Science+Business Media New York 2014

\begin{abstract}
Recent advances in our understanding of the molecular biology of salivary gland neoplasms have yielded diagnostic targets and potential therapeutic targets that have started to change our approach and choice of treatment strategies. Currently, these options are mainly investigated in recurrent and metastatic salivary gland cancer (SGC). Although the results of both cytotoxic and targeted molecular biological systemic therapy for locoregional recurrence and distant spread of SGC remain largely unpredictable, targeted therapy can be the treatment of choice in selected cases today. Molecular analysis is required as part of the diagnostic workup to help select patients with recurrent and metastatic SGC who may benefit from targeted or standard treatment regimens.
\end{abstract}

Keywords Salivary gland neoplasms $\cdot$ Salivary gland cancer · Molecular biology · Molecular markers . Chemotherapy $\cdot$ Targeted therapy

\footnotetext{
V. Vander Poorten $(\bowtie) \cdot J$. Meulemans $\cdot$ P. Delaere Otorhinolaryngology-Head and Neck Surgery, University Hospitals Leuven, Herestraat 49, Leuven 3000, Belgium e-mail: vincent.vanderpoorten@uzleuven.be URL: www.esgs.ch

J. Meulemans

e-mail: jeroen.meulemans@uzleuven.be

P. Delaere

e-mail: pierre.delaere@uzleuven.be

V. Vander Poorten $\cdot$ P. Delaere $\cdot$ S. Nuyts $\cdot$ P. Clement Leuven Cancer Institute, University Hospitals Leuven, Herestraat 49, Leuven 3000, Belgium

e-mail: sandra.nuyts@uzleuven.be

P. Clement

e-mail: paul.clement@uzleuven.be
}

\section{Introduction}

The annual incidence of salivary gland carcinomas ranges from 4 to 135 new patients per $10^{6}$ people, with the highest incidence rates reported in Greenland and the Canadian Arctic [1]. The US incidence is reported as 10 new patients per $10^{6}$ per year [2], and somewhat lower European incidences, such as reported in Finland, Belgium, The Netherlands and the UK, amount to about 6-7 per $10^{6}$ per year [3-6]. The major salivary glands give rise to $90-95 \%$ of these tumors, where $70 \%$ occur in the parotid and $20-25 \%$ in the submandibular and sublingual glands. Less than $10 \%$ arise in the minor salivary glands $[3,4,7-9]$.

This review focuses on recent advances in our understanding of the molecular biology of these rare cancers and aims at updating the reported experience with cytotoxic and targeted molecular biological agents in the recurrentmetastatic disease setting.

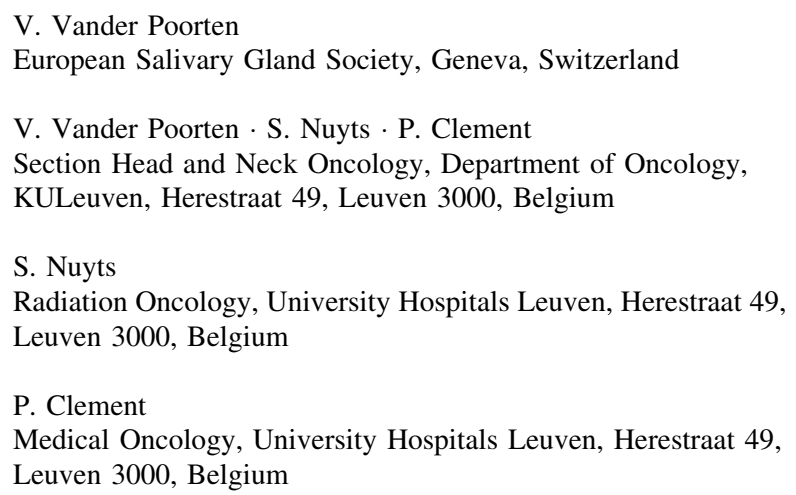




\section{Diagnosis: Histotyping and Grading}

In 2005, the World Health Organization (WHO) published the current reference classification featuring 24 different types of salivary gland cancer (SGC) [10]. The pathologist combines light microscopic features and immunohistochemistry to (1) assign a specific tumor to one of the categories in this classification (histotyping); (2) describe negative prognostic features (lymphovascular invasion, positive resection margins, perineural growth, etc.); and (3) for specific subtypes, to grade the tumor. Molecular markers are becoming increasingly important in the diagnostic fine-tuning of SGCs.

\section{Histotyping}

There is frequently no uniform relationship between histotype and biological behavior [11]. Only population-based studies give a true reflection of the distribution of the 24 histotypes. In such population-based studies, the majority of major SGCs are acinic cell carcinoma (AcCC: 15-17\%), adenoid cystic carcinoma (AdCC: 16-27\%), and mucoepidermoid carcinoma (MEC: 14.5-19 \%) [6, 12]. In most studies of minor SGCs, AdCC and MEC account for up to $89 \%$ of histologic types, and AdCC (32-71\%) and MEC (15-38 \%) far outnumber adenocarcinoma Not Otherwise Specified (ACNOS), AcCC, polymorphous low grade adenocarcinoma (PLGA), epithelial myoepithelial carcinoma, and carcinoma ex-pleomorphic adenoma (CXPA) [9]. Histotyping of SGCs is challenging, and marked by high reclassification rates following slide review of historical series. Examples are the $29 \%$ reclassification rate resulting from application of a new histologic classification system as reported by van der Wal et al. [13] and a $22 \%$ reclassification rate as reported in our own series [14]. A substantial interobserver variability between pathologists also exists [15]. Reclassification, interobserver variability, geographic variation and referral bias all contribute to disparities in the published histology distribution. For clinical purposes, we routinely divide the different histotypes into clinically low-grade (AcCC, PLGA and low-grade MEC), intermediate-grade (epithelial myoepithelial carcinoma and AdCC) and high-grade carcinomas (salivary duct carcinoma-SDC, ACNOS, high-grade MEC, CXPA and undifferentiated carcinoma). However, also the clinical grade assignment does not always parallel clinical behavior. This "clinical grading" has to be distinguished from the "histopathological" or "optical" grading described in the next paragraph.

\section{Histopathological Grading}

Optical grading by the pathologist is an attempt to explain variable biological behavior within tumors of the same histotype and is well established in the three most frequent salivary gland carcinomas: MEC [15-17], AcCC [18] and AdCC [19, 20]. However, grading shows poor inter- and intraexaminer consistency with a low independent prognostic power in multivariate analysis, because grading parallels other important prognostic factors that are more reliable to reproduce such as age, stage, perineural growth and irradical surgery [8].

\section{Molecular Biology in Diagnosis and Prognosis}

Molecular markers are a main focus of current salivary gland tumor research. As optical grading suffers from interobserver variation and is collinear with many other strong clinicopathological factors, molecular markers are being investigated for their potential prognostic role and may prove more reliable in predicting outcome. They are also under study as therapeutic targets.

\section{Cell Cycle-Based Proliferation Markers}

The endpoint of the accumulation of genetic and epigenetic changes that leads to deranged growth is reflected by the expression of cell cycle-based proliferation markers. Their expression parallels the number of cells going through the cell cycle toward division. Among cell-cycle based proliferation markers in SGC, well studied are the expressions of $\mathrm{Ki}-67$, an anti-apoptotic nuclear antigen in proliferating cells [21-23], proliferating cell nuclear antigen (PCNA, a co-factor of DNA polymerase) [24, 25], human telomerase reverse transcriptase (hTERT) [26] and AgNOR (argyrophylic nucleolar organizer region-associated proteins) [27, 28], as well as TUNEL [terminal deoxynucleotidyl transferase (TdT)-mediated dUTP-biotin nick end labeling] assays that identify DNA breaks in apoptotic cells [29]. The most widely used of these is the general overall proliferation marker Ki-67, which is widely applicable and correlates well with biological behavior [21]. Together with age and tumor stage, the Ki-67 index is an important and independent prognostic factor on multivariate analysis, irrespective of tumor subtyping, grading or morphological appearance of the salivary gland tumor [30••].

\section{Separately Studied Genetic and Epigenetic Changes}

At the basis of the deranged growth (that is reflected by the cell cycle-based proliferation markers just mentioned) is an accumulation of genetic and epigenetic changes, which are all elements of the cascade that ultimately results in uncontrolled growth. Many of these elements have been studied separately, but the prognostic value can be confirmed only if they remain independent on multivariate 
Table 1 Molecular targets and bullets in SGC

\begin{tabular}{|c|c|c|}
\hline Molecular target & SGC type & Molecular therapy \\
\hline $\mathrm{c}-\mathrm{KIT}$ & AdCC & $\begin{array}{l}\text { Imatinib }[31,32,34-36,42] \\
\quad \text { sunitinib }[133]\end{array}$ \\
\hline EGFR, ErbB-1 & All types & $\begin{array}{r}\text { Cetuximab [51]; } \\
\text { gefinitib [134] }\end{array}$ \\
\hline HER2/neu, ErbB-2 & All types & $\begin{array}{l}\text { Trastuzumab }\left[39,40,135^{\bullet}\right] \\
\quad \text { lapatinib }[33]\end{array}$ \\
\hline $\begin{array}{l}\text { NFאB-proteasomes } \\
\text { degrading its } \\
\text { inhibitor }(\mathrm{I}-\kappa \mathrm{K}-\alpha)\end{array}$ & AdCC & Bortezomib [41] \\
\hline VEGF & AcCC & Axinitib [136] \\
\hline
\end{tabular}

Modified from [9] with permission

analyses. Some of these markers have also been investigated as therapeutic targets, and these are tabulated in Table 1 [31-43]. For the description of these markers, we grouped them using a similar structure as in our previous review paper on parotid carcinoma [8].

\section{Growth Factor Receptor Proteins and Their Ligands}

Stem cell factor receptor (c-KIT, a transmembrane tyrosine kinase), angiogenesis-related growth factor receptors (VEGF-R, PDGF-R, bFGF-R, IL-8, PIGF, TGF $\beta$, EphA2), nerve growth factor (NGF), the ErbB/HER family of human epidermal growth factor receptors (EGFR also named HER-1 or ErbB-1; HER-2 or HER2/Neu or ErbB-2; HER-3 or ErbB-3; HER-4 or ErbB-4), insulin-like growth factors (IGF-I/II) and receptor (IGF-1R) and receptor tyrosine kinase MET and its ligand hepatocyte growth factor can be put in this category.

c-KIT is detected in 80-94\% of AdCC [44] and in $100 \%$ of lymphoepithelial-like salivary gland carcinomas and myoepithelial carcinomas, and in a subset of other tumors as well [44]. In AdCC, the relation between high c-KIT expression $(>50 \%)$ and grade has been widely discussed and remains unresolved. In one study this feature was significantly more common in grade 3 or solid-type AdCC [45], but Freier et al. [46] found the opposite: high expression only in cribriform and tubular AdCC.

For angiogenesis-related growth factor receptors, Lim et al. [47] describe the prognostic value for VEGF expression, which is found in many SGCs. In multivariate analyses, VEGF expression was associated with advanced stage and worse DSS [48]. Greater expression of EphA2, a receptor tyrosine kinase involved in angiogenesis, and its ligand ephrin A1 has recently been described in AdCC, where expression correlates to microvessel density, TNM stage, perineural invasion and vascular invasion. This expression is significantly greater in solid type AdCC than in the cribriform and tubular types [49].
In the human epidermal growth factor receptor family, EGFR identification and overexpression correlate with aggressiveness in MEC [50], SDC [51, 52] and AdCC [50, 51]. Although EGFR protein expression is common in SGC, it is not associated with gene amplification [53]. Activating mutations of EGFR are rare in SGC, but when present, they may be linked to good response to anti-EGFR therapy in a way similar to what is observed in non-small cell lung cancer [53]. A recent study by Lee et al. [54] was not able to link the expression of EGFR, c-KIT and VEGF to prognosis in AdCC. HER-2 has been found overexpressed in AdCC, SDC [52, 55, 56], CXPA [57] and about $30 \%$ of MEC [25, 38, 50, 58, 59]. Furthermore, it is a negative prognostic marker in multivariate analysis, independent of histopathological grade, tumor size and involvement of regional lymph nodes [59]. Aggressively behaving AdCCs also display HER-3 expression [50].

Increased expression of NGF, besides increased VEGF expression, has been described in AdCC, possibly accounting for its neurotropism [60]. In the same line, recently Ivanov et al. [61・•] observed overexpression of a large cluster of neuronal genes grouped around $\mathrm{TrkC} /$ NTRK3, a tyrosine kinase neurotrophic receptor associated with neurogenesis and cancer, in AdCC. This finding suggests that AdCC aberrantly expresses genes involved in neural stem cell differentiation.

The receptor tyrosine kinase MET and its ligand, the hepatocyte growth factor, activate different cellular signaling pathways leading to tumor cell proliferation, migration, motility and invasion. In SGC, aberrations of genomic MET are associated with lymphatic spread and are characteristic for high-risk tumors with poor overall survival [62•]. Multivariate analysis showed that aberration of MET is a very strong predictor of lymph node metastasis, even stronger than the established criteria of tumor size and grade [63].

\section{Cell Cycle Oncogenes}

The above-mentioned growth factor-receptor interaction activates cell cycle oncogenes, including sex-determining region Y-box 4 and 10 (SOX-4, SOX-10), nuclear factor $\kappa \mathrm{B}(\mathrm{NF \kappa B})[64,65]$, human rat sarcoma viral oncogene homolog (H-RAS), phosphatidylinositol 3 phosphate kinase/serine-threonine protein kinase Akt (PI3 K/AKT) [65], sarcoma (Schmidt-Ruppin A-2) viral oncogene homolog ( $\mathrm{Src}$ ), signal transducer and activator of transcription 3 (STAT3), mammalian target of rapamycin [mTOR, activated by AKT, regulating protein synthesis depending on nutrient availability and negatively regulated by the tumor suppressor gene phosphatase and tensin homolog (PTEN)], peroxisome proliferator-activated receptor gamma $\left(\mathrm{PPAR}^{\gamma}\right)$ [66] and cyclin D1. 
In a large microarray analysis of AdCC, Frierson et al. [67] found that SOX-4 was the most significantly overexpressed cell cycle oncogene. Furthermore, increased apoptosis following SOX-4 knockdown suggests that this oncogene exerts its activity via downregulation of inhibitors of the NFאB pathway (inhibitor protein $\mathrm{I}-\kappa \mathrm{B}-\alpha$ ) and by upregulation of apoptosis inhibitors such as survivin [68]. More recently, the transcriptional factor SOX-10, normally only expressed during salivary gland differentiation, was found markedly upregulated in a great majority of AdCC cells [69]. Mutations of H-RAS are observed in CXPA [70], ACNOS [71] and almost half of MECs, where the frequency of H-RAS mutations parallels tumor grade [72]. Cyclin D1 seems frequently overexpressed in AdCC and MEC and correlates to prognosis [73, 74]. In MEC, high cyclin D1 expression follows inactivation of secreted frizzled-related proteins (SFRPs) by hypermethylation [74]. Nuclear STAT3 expression seems to play a role as a tumor suppressor in the absence of EGFR, HER-2 and survivin in SGC [52]. RUNX3, a tumor suppressor gene that, when active, facilitates TGF-beta to play its apoptotic role, appears silenced by hypermethylation in AdCC [75]. Expression of PDCD4 (programmed cell death 4), a recently described tumor suppressor gene inhibiting neoplastic transformation and tumor promotion/progression, is downregulated in the majority of AdCCs. Decreased PDCD4 expression is also significantly associated with the clinical stage of the disease and poor prognosis. Multivariate analysis demonstrated that PDCD4 expression is an independent risk factor for AdCC [76•]. Suprabasin (SBSN), a novel oncogene in AdCC, plays important roles in maintaining cell proliferation and invasive metastatic capability in AdCC. Moreover, the expression of SBSN is upregulated by $\mathrm{CpG}$ island demethylation, and hypomethylation of SBSN is significantly more frequent in AdCC than in normal salivary gland tissues [77]. RB1-inducible coiled-coil 1 (RB1CC1) is a positive regulator for the retinoblastoma tumor suppressor (RB1) pathway, and its expression in SGCs appears to imply better prognosis, analogous to what has been shown for breast cancer [78]. Expression of ERBB3-binding protein 1 (EBP1), a molecule with multiple roles in cell proliferation and differentiation, was found to be inversely correlated with local invasion and distant spread of AdCC. Patients with lower EBP1 levels had poorer long-term survival than those with higher EBP1 expression, and this follows the upregulation of E-cadherin by EBP1, inhibiting the migration and invasiveness of AdCC [79]. The PI3K/AKT/mTOR (mammalian target of rapamycin) axis plays a critical role in tumorigenesis. Dysregulation of this molecular pathway involves alterations of AKT, mTOR, PTEN and various upstream tumor-associated growth factors (EGFR, HER-2, PDGF and VEGF) [80]. Loss of PTEN goes along with stimulation of the PI3K pathway, promoting cell survival and tumor growth, resulting in cell migration and metastasis by deregulation of cell interactions with the extracellular matrix. Loss of PTEN has been described in a subset of highly malignant SGCs and was assocciated with high levels of EGFR and HER2 [81•]. Recently, deletion of PTEN was found a strong predictor of neck node metastasis, remaining so in multivariate analysis [63]. Efforts are underway at targeting the PI3K/AKT pathway by blocking mTOR with temsirolimus [82].

Pleomorphic adenoma gene 1 (PLAG1) is a specific proto-oncogene found in a large percentage of pleomorphic adenomas and is transcribed and overexpressed following a $\mathrm{t}(3 ; 8)(\mathrm{p} 21 ; \mathrm{q} 12)$ chromosome translocation resulting in $\beta$-catenin-promoter swapping. This causes deregulated expression of PLAG1 target genes by the IGF-II IGFIR mitogenic signaling pathway [83]. Another fusion oncogene, MEC translocated 1 gene with exons 2-5 of the mastermind-like gene 2(MECT1-MAML2); $\mathrm{t}(11 ; 19)(\mathrm{q} 14-21 ; \mathrm{p} 12-13)$ [84] is transcribed into a fusion protein that was initially thought to be exclusively seen in low-grade MEC histology [85, 86]. However, highgrade fusion-positive MECs associated with advancedstage lethal disease have now been described [87]. For AdCC, a recurrent reciprocal translocation of $\mathrm{t}(6 ; 9)(\mathrm{q} 22-23 ; \mathrm{p} 23-24)$ resulting in fusion gene partners comprising the MYB gene and the transcription factor NFIB (previously reported in AdCC of the breast, lacrimal and ceruminal glands) has now been described. In both fusion-positive and a subset of fusion-negative AdCCs, high expression of the transcript Myb was found, suggesting this as a potential target for new therapies [88].

\section{Proteins Involved in DNA Damage Repair}

p53 and ERCC1 (excision repair cross-complementation group 1) belong in this category. p53 expression [89] and p53 mutations in AdCC are generally associated with worse outcome [90], but a large Finnish multivariate analysis failed to confirm this information as having additional value over a classical clinicopathological multivariate model. This large study however did not focus on the AdCC subgroup but studied all SGC types [91].

\section{Proteins Involved in Apoptosis}

The Bcl-2 group contains pro-apoptotic proteins such as Bax, Bad and Bak and anti-apoptotic proteins such as Bcl-2, Bcl-xL and survivin. High Bcl-2 expression in SGC relates to poor prognosis and advanced $\mathrm{T}$ and $\mathrm{N}$ classification [92]. Nuclear survivin expression indicates aggressive SGC with worse prognosis [52]. 
Proteins involved in cell-cell adhesion (hemidesmosome proteins $B 180$ and B230, E- and N-cadherin, CDH12, $\alpha$ catenin, mammalian ENA, CD44 and CD24) [93-98], migration (matrix metalloproteinase, heparanase, CD147 or extracellular matrix metalloproteinase inducer or Emmprin) [11, 99-102] and epithelial-mesenchymal transition (NBS-1 and snail)

Matrix metalloproteinase 9 (MMP-9) degrades type IV collagen, a major component of basement membranes in human tissues, and allows the tumor cells to break through the site of the primary tumor, leading to invasion and metastasis. MMP-9 was recently found to be overexpressed in SDC, together with tumor cell-associated extracellular MMP inducer, CD147, which regulates the expression level and activity of MMP-9 and MMP-2. High expression of CD147 and MMP-9 was significantly correlated with invasion, metastasis, shorter progression-free survival and shorter overall survival (poor prognosis) compared with SDC patients with low CD147/MMP-9 expression [102]. Recent research identified an association between ILK (integrin linked kinase) and epithelial-mesenchymal transition markers in adenoid cystic carcinoma (AdCC). ILK plays a key role in cell-extracellular matrix interactions, regulating cell proliferation, apoptosis, differentiation and migration. Positive expression of ILK correlates strongly with solid-type AdCC, advanced TNM stage and increased risk of recurrence. Moreover, upregulation of Snail and $\mathrm{N}$-cadherin and downregulation of E-cadherin correlated significantly with ILK overexpression and a neural invasive phenotype. Through epithelial-mesenchymal transition by upregulation of Snail, downregulation of E-cadherin and upregulation of $\mathrm{N}$-cadherin, ILKs may have an important role in progression and metastasis in AdCC [103].

\section{Estrogen, Progesterone and Androgen Receptors [51, 66, $104 \bullet$ ]}

Estrogen receptors have been described in AdCC, whereas androgen receptors have been the target of hormonal therapy in SDC. In a study that examined 139 cases of SGC, androgen receptor expression was found in $13 \%$, but no expression of estrogen or progesterone receptor was detected [105•].

\section{Markers for Lymphangiogenesis}

Podoplanin (T1a-2, aggrus or gp36) is a small mucin-like protein and its function is related to tissue development and repair. It is specifically expressed in lymphatic endothelial cells and is used as a specific marker for lymphangiogenesis. It is also expressed in certain tumor cells and is associated with migration/invasion in cervix and oral squamous cell carcinoma. Recently, Podoplanin was found to be overexpressed in a subset of salivary gland AdCCs (32.5\% of tumors). Overexpression was significantly associated with disease-free survival and distant metastasis, although it was not associated with recurrence and overall survival [106].

\section{Viral Etiology}

Recently the interesting hypothesis was put forward that the hCMV virus is implied in the oncogenesis of MEC. This awaits further validation in larger series, but the authors found the viral protein expressed in almost all cases studied [107•].

\section{Transcription Factors}

In AdCC, significant epigenetic changes (hypermethylation) were observed at the transcriptional start sites of genes that encode for the transcription factor Engrailed homeobox 1 (EN1), which plays an important role in the development of the central nervous system. Hypermethylation of EN1 correlates with histologic tumor grade, tumor location and final patient outcome in AdCC [108]. Moreover, EN1 protein expression was typical for solid type AdCC and implied a significantly lower survival rate, making EN1 a potential biomarker in AdCC [109].

\section{Treatment with Cytotoxic Chemotherapy in the Palliative Setting}

In advanced SGC, no standard systemic treatment is available. Cytotoxic chemotherapy is generally used in the context of a palliative therapy, based on level 3 evidence (case-control or cohort studies). The data supporting the use of chemotherapy are scarce, because trials involve small populations with important heterogeneity regarding the histology, prior systemic therapies and proportion of patients with locoregional recurrence versus distant metastasis. Moreover, the majority of SGCs have a slow growth pattern, making it difficult to assess the response of the tumor to chemotherapy.

\section{Monotherapy (Single-Agent Chemotherapy)}

Cisplatin is the most extensively studied single-agent chemotherapy for advanced SGC. The largest phase II study included 25 patients with AdCC, MEC and ACNOS and showed a mean response rate of $18 \%$, response duration between 5 and 9 months, and a median overall survival time of 14 months [110]. On the other hand, De Haan et al. [111], including ten patients with advanced 
AdCC, observed no objective responses: five patients showed stabilization of their disease for a median duration of 20 months.

In AdCC, mitoxantrone, epirubicin and vinorelbin all appear to have activity as a single agent. In a study including 32 AdCC patients, mitoxantrone induced a partial response in four patients, lasting from 3 to 13 months, and 22 patients had stable disease [112]. Although treatment with epirubicin yielded a rapid improvement in disease-related symptoms in $29 \%$ of patients in a phase II trial including 20 patients with advanced or recurrent AdCC, the response rate remained low $(10 \%)$ and the median time to disease progression short (16 weeks) [113]. Vinorelbin has moderate activity in AdCC and ACNOS with overall response rates of $20 \%$, median partial response duration of 6 months, median time to disease progression of 5 months, median stable disease duration of 3.5 months and median overall survival of 8.5 months [114]. In a study by Gilbert et al., paclitaxel did not show any activity in AdCC, but it appears to provide some objective responses in MEC and ACNOS [115]. Gemcitabine monotherapy showed no objective responses in AdCC [116].

\section{Combination Therapy}

The most studied regimen in the treatment of advanced SGC is CAP (cyclophosphamide, doxorubicin and cisplatin) [117]. A phase II trial by Licitra et al. [118], treating 22 patients with advanced SGC (AdCC and non-AdCC), achieved partial responses in only six patients, with an overall response rate of $27 \%$. In our patients with metastatic ACNOS treated with CAP, we observed a $60 \%$ response rate, but the responses were generally short-lived with a median time to progression of 6.6 months [119].

Tsukuda et al. [120] documented a $36 \%$ response in 14 patients with ACNOS or AdCC treated with CPPr (cyclophosphamide, cisplatin and pirabucin, a less cardiotoxic anthracycline analog). In a series of 17 patients treated with PAF (cisplatin, doxorubicin and 5-fluorouracil), overall response was $35 \% \quad(12 \%$ complete, $23 \%$ partial response), with response duration of 6 up to 15 months but no survival advantage [121]. A combination treatment of cisplatin, epirubicin and 5-fluorouracil (PEF) did not do better than cisplatin monotherapy (one partial response out of eight patients) [122]. Evaluating FACP (5-fluorouracil, doxorubicin, cyclophosphamide and cisplatin) in 17 patients with advanced SGC, the objective response rate was $50 \%$ (44\% partial, $6 \%$ complete response) with a median duration of 7 months, but with a higher toxicity than three-agent regimens [123]. A small randomized study compared vinorelbine with a combination of vinorelbinecisplatin (PV) in 16 patients with recurrent SGC of all three major histologic subtypes. Overall response of the PV regimen was $44 \%$. Median duration of complete response was 15 months and of partial response 7.5 months, making PV better than vinorelbine in monotherapy. Compared to CAP, PV could be less toxic and equally effective [114]. A combination of carboplatin and paclitaxel only achieved two partial responses in 14 patients with SGC, resulting in a median survival of 12.5 months [124].

More recently, Laurie et al. evaluated a gemcitabinecisplatin/carboplatin (GP) regimen in 33 patients with advanced SGC. The response rate was $24 \%$, median response duration 6.7 months. Thus, GP demonstrates modest activity in advanced SGC but no advantage over other cisplatin-based regimens (e.g., CAP) [125].

In conclusion, whether or not combination chemotherapy is better than monotherapy for SGC is still uncertain. Combination regimens generally result in higher response rates at the cost of additional toxicity, but fail to improve survival [126]. A recent high-quality meta-analysis focusing on locally recurrent or metastatic AdCC reaches the same conclusion [127••]. This study evaluated the activity of combination chemotherapy in 143 patients enrolled in 17 trials. In 14 studies, cisplatin-based regimens led to objective responses in 29 of 118 patients (response rate $25 \%$ ). Response duration ranged widely, from 6 to 77 months.

\section{Treatment with Cytotoxic Chemotherapy in the Curative Setting}

Recently, two reports documented the benefit of a postoperative platinum-based concomitant chemoradiation scheme for high-risk major salivary gland carcinomas [128, 129].

These are preliminary reports that still need validation given the clearly higher toxicity this approach entails.

\section{Treatment with Targeted Therapies}

The explored targeted therapies are listed in Table 1 .

Imatinib

Although c-KIT is overexpressed in up to $94 \%$ of AdCCs, results of treatment with imatinib (c-KIT tyrosine kinase inhibitor) are disappointing. Imatinib as a single agent was evaluated in 5 studies including 54 patients [31, 32, 34, 42, 130]. Stable disease was observed in 19 patients (35\%). Only two objective responses were reported (3.7 \%), both in a study requiring progressive disease and high c-KIT expression for inclusion [42]. One phase II study, 
evaluating the combination imatinib/cisplatin in 28 patients with locally advanced and metastatic AdCC, showed a partial response in 3 of 28 patients, while 19 patients (68\%) had disease stabilization [131].

\section{Lapatinib}

Lapatinib, a dual inhibitor of EGFR and HER-2 tyrosine kinase activity, was evaluated in 40 patients with progressive metastatic or recurrent SGC with proven EGFR/ HER-2 overexpression. Although no objective responses were seen, disease stabilization for at least 6 months was observed in 13 patients $(32.5 \%)$. Because disease progression was needed to meet the inclusion criteria, the disease stabilization was likely due to the effect of lapatinib [33].

\section{Gefitinib}

Despite the common EGFR expression in SGC, the orally active EGFR tyrosine kinase inhibitor gefitinib performs poorly in patients with advanced SGC. A phase II study including 28 patients with advanced SGC reported no objective responses and stable disease in 14 patients, with a median duration of 3 months. Of the latter, 13 patients had AdCC, typically behaving in an indolent way, making "stable disease" an unreliable endpoint [132].

\section{Bortezomib}

Bortezomib inhibits the proteasome that normally degrades the $N F \kappa B$ inhibitor $(I-\kappa B-\alpha)$. In this way, $N F \kappa B$, related to angiogenesis and poor patient outcome, is inhibited. Bortezomib was tested in a phase II trial including 24 patients with recurrent or metastatic AdCC, but no objective responses were observed. Fifteen of 21 evaluable patients (71\%) showed disease stabilization for a median duration of 4.2 months and an overall survival of 21 months. In ten patients, doxorubicin was added at disease progression, leading to one partial response and five disease stabilizations (median duration, 5.2 months) [41].

\section{Sunitinib}

The antitumor activity of sunitinib, a multitarget inhibitor of VEGF-R, PDGF-R, c-KIT, ret proto-oncogene (RET) and FMS-like tyrosine kinase 3 (FLT3), was assessed in a phase II study. In 13 patients with recurrent and/or metastatic AdCC, no objective responses were seen, and 11 patients showed stable disease, in 8 patients stable for minimally 6 months. Median time to progression was 7.2 months, while median overall survival was 18.7 months [133].
Cetuximab

The anti-EGFR monoclonal antibody cetuximab was evaluated in a phase II trial including 30 patients with advanced SGC [37]. No objective responses were reported, but stable disease was recorded in 24 (80\%) patients, lasting for more than 6 months in 15 of them. Molecular analysis showed no EGFR gene amplification, and just $12 \%$ of AdCCs showed an increase in the EGFR gene copy number. Clauditz et al. confirm this finding that, although EGFR protein expression is common in SGC, EGFR gene amplification and activating mutations are rare. Several studies, e.g., in non-small cell lung cancer, suggest a predictive role of the EGFR copy number for anti-EGFR therapy response, so selected cases of patients with advanced SGC and an increased EGFR copy number might derive more benefit from anti-EGFR therapy [53].

\section{Trastuzumab}

Trastuzumab, a monoclonal antibody interfering with the HER-2 receptor, was tested for the first time in a phase II trial by Haddad et al. in advanced SGC overexpressing HER-2. The study closed early because of the low rate of HER-2 overexpression in the SGC screened for study entry. One objective partial response in a patient with MEC lasted for more than 2 years, but the rest showed disease progression after a median time of 4.2 months, so the conclusion was that trastuzumab is not active in advanced SGC [39]. Nabili et al. [40] reported one complete response in three patients treated with trastuzumab for progressive SDC. Limaye et al. [43] recently retrospectively assessed trastuzumab combined with paclitaxel and carboplatin in an adjuvant or palliative setting in 13 patients with HER-2 positive SDC. All patients with metastatic disease (5 patients) responded for a median duration of 18 months; one patient achieving a complete response remained free of disease 52 months after initiation of therapy.

\section{Conclusion}

Recent advances in our understanding of the molecular biology of SGC have yielded diagnostic targets and also potential therapeutic targets for patients with locally recurrent or metastatic disease, but to date, the results of systemic treatment by means of cytotoxic chemotherapy or targeted molecular therapies remain modest. At best, temporary, usually partial, disease response or stabilization can be achieved before disease progression occurs. Multiinstitutional and international collaborative efforts to collect and share tumor samples through tissue banks will be necessary to provide the tissue material needed for 
assessment and validation of diagnostic and prognostic molecular biological advances and to perform multicenter trials of potentially promising new treatment strategies.

\section{Compliance with Ethics Guidelines}

Conflict of Interest Vincent Vander Poorten, Jeroen Meulemans, Pierre Delaere, Sandra Nuyts and Paul Clement declare no conflicts of interest.

Human and Animal Rights and Informed Consent This article does not contain any studies with human or animal subjects performed by the authors.

\section{References}

Recently published papers of particular interest have been highlighted as:

- Of importance

-. Of major importance

1. Albeck H, Nielsen NH, Hansen HE, et al. Epidemiology of nasopharyngeal and salivary gland carcinoma in Greenland. Arctic Med Res. 1992;51(4):189-95.

2. Spiro JD, Spiro RH. Salivary tumors. In: Shah JP, Patel SG, editors. Cancer of the head and neck. 1st ed. Hamilton: Decker BC Inc; 2001. p. 240-50.

3. Van Eycken L. Head and neck cancer. In: Van Eycken L, editor. Cancer incidence in Belgium 2004-2005. Belgian cancer registry; 2008: 41.

4. Coebergh JWW, van der Heijden LH, Janssen-Heijnen MLG. Cancer of the salivary gland. In: Coebergh JWW, van der Heijden LH, Janssen-Heijnen MLG, editors. Cancer incidence in the southeast of the Netherlands 1955-1994, a report from the Eindhoven cancer registry. Eindhoven: Comprehensive Cancer Center South; 1995. p. 24.

5. Bradley PJ. General epidemiology and statistics in a defined UK population. In: Mc Gurk M, Renehan A, editors. Controversies in the management of salivary gland disease. 1st ed. Oxford University Press: Oxford; 2001. p. 3-12.

6. Luukkaa H, Klemi P, Leivo I, et al. Salivary gland cancer in Finland 1991-1996: an evaluation of 237 cases. Acta Otolaryngol. 2005;125(2):207-14.

7. Spiro RH. Salivary neoplasms: overview of a 35-year experience with 2,807 patients. Head Neck. 1986;8(3):177-84.

8. Vander Poorten V, Bradley PJ, Takes RP, Rinaldo A, Woolgar JA, Ferlito A. Diagnosis and management of parotid carcinoma with a special focus on recent advances in molecular biology. Head Neck. 2012;34(3):429-40.

9. Vander Poorten V, Hunt J, Bradley PJ et al. Recent trends in the management of minor salivary gland carcinoma. Head Neck 2013. doi:10.1002/hed.23249.

10. Barnes L, Eveson JW, Reichart P, Sidranski P. Pathology and genetics of head and neck tumours. World Health Classification of Tumours. In: IARC, editor. Lyon: IARC press; 2005:210.

11. Leivo I. Insights into a complex group of neoplastic disease: advances in histopathologic classification and molecular pathology of salivary gland cancer. Acta Oncol. 2006;45(6):662-8.

12. Vander Poorten VL, Hart AA, van der Laan BF et al. Prognostic index for patients with parotid carcinoma: external validation using the nationwide 1985-1994 Dutch Head and Neck
Oncology Cooperative Group database. Cancer 2003; 97(6): 1453-1463.

13. van der Wal JE, Snow GB, van der Waal I. Histological reclassification of 101 intraoral salivary gland tumours (new WHO classification). J Clin Pathol. 1992;45(9):834-5.

14. Vander Poorten VLM, Balm AJM, Hilgers FJM, Tan IB, Keus RB, Hart AAM. Stage as major long term outcome predictor in minor salivary gland carcinoma. Cancer. 2000;89(6):1195-204.

15. Brandwein MS, Ivanov K, Wallace DI, et al. Mucoepidermoid carcinoma: a clinicopathologic study of 80 patients with special reference to histological grading. Am J Surg Pathol. 2001;25(7): 835-45.

16. Seifert G, Sobin LH. The World Health Organization's histological classification of salivary gland tumors. A commentary on the second edition. Cancer. 1992;70:379-85.

17. Evans HL. Mucoepidermoid carcinoma of salivary glands: a study of 69 cases with special attention to histologic grading. Am J Clin Pathol. 1984;81(6):696-701.

18. Batsakis JG, Luna MA, El-Naggar AK. Histopathologic grading of salivary gland neoplasms: II. Acinic cell carcinomas. Ann Otol Rhinol Laryngol. 1990;99(11):929-33.

19. Perzin KH, Gullane P, Clairmont AC. Adenoid cystic carcinomas arising in salivary glands: a correlation of histologic features and clinical course. Cancer. 1978;42(1):265-82.

20. Spiro RH, Huvos AG. Stage means more than grade in adenoid cystic carcinoma. Am J Surg. 1992;164(6):623-8.

21. Nordgard S, Franzen G, Boysen M, Halvorsen TB. Ki-67 as a prognostic marker in adenoid cystic carcinoma assessed with the monoclonal antibody MIB1 in paraffin sections. Laryngoscope. 1997;107(4):531-6.

22. Goode RK, Auclair PL, Ellis GL. Mucoepidermoid carcinoma of the major salivary glands: clinical and histopathologic analysis of 234 cases with evaluation of grading criteria. Cancer. 1998;82(7):1217-24.

23. Triantafillidou K, Dimitrakopoulos J, Iordanidis F, Koufogiannis D. Management of adenoid cystic carcinoma of minor salivary glands. J Oral Maxillofac Surg. 2006;64(7):1114-20.

24. Frankenthaler RA, el Naggar AK, Ordonez NG, Miller TS, Batsakis JG. High correlation with survival of proliferating cell nuclear antigen expression in mucoepidermoid carcinoma of the parotid gland. Otolaryngol Head Neck Surg. 1994;111(4):460-6.

25. Lopes MA, da Cruz Perez DE, de Abreu AF, de Almeida OP, Kowalski LP. Clinicopathologic and immunohistochemical study of intraoral mucoepidermoid carcinoma. Otolaryngol Head Neck Surg. 2006;134(4):622-6.

26. Zang G, Miao L, Mu Y, et al. Adenoviral mediated transduction of adenoid cystic carcinoma by human TRAIL gene driven with hTERT tumor specific promoter induces apoptosis. Cancer Biol Ther. 2009;8(10):966-72.

27. Xie X, Nordgard S, Halvorsen TB, Franzen G, Boysen M. Prognostic significance of nucleolar organizer regions in adenoid cystic carcinomas of the head and neck. Arch Otolaryngol Head Neck Surg. 1997;123(6):615-20.

28. Alaeddini M, Khalili M, Tirgary F, Etemad-Moghadam S. Argyrophilic proteins of nucleolar organizer regions (AgNORs) in salivary gland mucoepidermoid carcinoma and its relation to histological grade. Oral Surg Oral Med Oral Pathol Oral Radiol Endod. 2008;105(6):758-62.

29. Ben-Izhak O, Laster Z, Araidy S, Nagler RM. TUNEL-an efficient prognosis predictor of salivary malignancies. $\mathrm{Br} \mathrm{J}$ Cancer. 2007;96(7):1101-6.

30. • Larsen SR, Bjorndal K, Godballe C, Krogdahl A. Prognostic significance of Ki-67 in salivary gland carcinomas. J Oral Pathol Med 2012; 41(8):598-602. This is a great study using a large cohort of SGC patients, showing once more the usefulness of Ki67 determination for prognosticating in SGC. The authors nicely 
test the additional value of this factor by introducing the Ki-67 score in a multivariable model including known clinical and pathological prognostic factors, following which only age and UICC stage remain in the final multivariable model.

31. Pfeffer MR, Talmi Y, Catane R, Symon Z, Yosepovitch A, Levitt M. A phase II study of imatinib for advanced adenoid cystic carcinoma of head and neck salivary glands. Oral Oncol. 2007;43(1):33-6.

32. Hotte SJ, Winquist EW, Lamont E, et al. Imatinib mesylate in patients with adenoid cystic cancers of the salivary glands expressing c-kit: a Princess Margaret Hospital phase II consortium study. J Clin Oncol. 2005;23(3):585-90.

33. Agulnik M, Cohen EW, Cohen RB, et al. Phase II study of lapatinib in recurrent or metastatic epidermal growth factor receptor and/or erbB2 expressing adenoid cystic carcinoma and non adenoid cystic carcinoma malignant tumors of the salivary glands. J Clin Oncol. 2007;25(25):3978-84.

34. Ochel HJ, Gademann G, Rocken C, Wordehoff H. Effects of imatinib mesylate on adenoid cystic carcinomas. Anticancer Res. 2005;25(5):3659-64.

35. Lin CH, Yen RF, Jeng YM, Tzen CY, Hsu C, Hong RL. Unexpected rapid progression of metastatic adenoid cystic carcinoma during treatment with imatinib mesylate. Head Neck. 2005;27(12):1022-7.

36. Ghosal N, Mais K, Shenjere P, et al. Phase II study of cisplatin and imatinib in advanced salivary adenoid cystic carcinoma. $\mathrm{Br}$ J Oral Maxillofac Surg. 2011;49(7):510-5.

37. Locati LD, Bossi P, Perrone F, et al. Cetuximab in recurrent and/ or metastatic salivary gland carcinomas: a phase II study. Oral Oncol. 2009;45(7):574-8.

38. Glisson B, Colevas AD, Haddad R, et al. HER2 expression in salivary gland carcinomas: dependence on histological subtype. Clin Cancer Res. 2004;10(3):944-6.

39. Haddad R, Colevas AD, Krane JF, et al. Herceptin in patients with advanced or metastatic salivary gland carcinomas. A phase II study. Oral Oncol. 2003;39(7):724-7.

40. Nabili V, Tan JW, Bhuta S, Sercarz JA, Head CS. Salivary duct carcinoma: a clinical and histologic review with implications for trastuzumab therapy. Head Neck. 2007;29(10):907-12.

41. Argiris A, Ghebremichael M, Burtness B, Axelrod RS, Deconti RC, Forastiere AA. A phase 2 trial of bortezomib followed by the addition of doxorubicin at progression in patients with recurrent or metastatic adenoid cystic carcinoma of the head and neck: a trial of the Eastern Cooperative Oncology Group (E1303). Cancer. 2011;117(15):3374-82.

42. Guigay JM, Bidault F, Temam S, Janot F, Raymond E, Faivre S. Antitumor activity of imatinib in progressive, highly expressing KIT adenoid cystic carcinoma of the salivary glands: a phase II study. J Clin Oncol. 2007;25(18):6068.

43. Limaye SA, Posner MR, Krane JF, et al. Trastuzumab for the treatment of salivary duct carcinoma. Oncologist. 2013;18(3): 294-300.

44. Jeng YM, Lin CY, Hsu HC. Expression of the c-kit protein is associated with certain subtypes of salivary gland carcinoma. Cancer Lett. 2000;154(1):107-11.

45. Holst VA, Marshall CE, Moskaluk CA, Frierson HF Jr. KIT protein expression and analysis of c-kit gene mutation in adenoid cystic carcinoma. Mod Pathol. 1999;12(10):956-60.

46. Freier K, Flechtenmacher C, Walch A, et al. Differential KIT expression in histological subtypes of adenoid cystic carcinoma (ACC) of the salivary gland. Oral Oncol. 2005;41(9):934-9.

47. Lim JJ, Kang S, Lee MR, et al. Expression of vascular endothelial growth factor in salivary gland carcinomas and its relation to $\mathrm{p} 53$, Ki-67 and prognosis. J Oral Pathol Med. 2003;32(9):552-61.

48. Lequerica-Fernandez P, Astudillo A, de Vicente JC. Expression of vascular endothelial growth factor in salivary gland carcinomas correlates with lymph node metastasis. Anticancer Res. 2007;27(5B):3661-6.

49. Shao Z, Zhu F, Song K, Zhang H, Liu K, Shang Z. EphA2/ ephrinA1 mRNA expression and protein production in adenoid cystic carcinoma of salivary gland. J Oral Maxillofac Surg. 2013;71(5):869-78.

50. Gibbons MD, Manne U, Carroll WR, Peters GE, Weiss HL, Grizzle WE. Molecular differences in mucoepidermoid carcinoma and adenoid cystic carcinoma of the major salivary glands [In Process Citation]. Laryngoscope. 2001;111(8):138-1373.

51. Locati LD, Bossi P, Perrone F, et al. Cetuximab in recurrent and/ or metastatic salivary gland carcinomas: a phase II study. Oral Oncol. 2009;45(7):574-8.

52. Ettl T, Stiegler C, Zeitler K, et al. EGFR, HER2, survivin, and loss of pSTAT3 characterize high-grade malignancy in salivary gland cancer with impact on prognosis. Hum Pathol. 2011; 43(6):921-31.

53. Clauditz TS, Gontarewicz A, Lebok P, et al. Epidermal growth factor receptor (EGFR) in salivary gland carcinomas: potentials as therapeutic target. Oral Oncol. 2012;48(10):991-6.

54. Lee SK, Kwon MS, Lee YS, et al. Prognostic value of expression of molecular markers in adenoid cystic cancer of the salivary glands compared with lymph node metastasis: a retrospective study. World J Surg Oncol. 2012;10:266.

55. Clauditz TS, Reiff M, Gravert L, et al. Human epidermal growth factor receptor 2 (HER2) in salivary gland carcinomas. Pathology. 2011;43(5):459-64.

56. Williams MD, Roberts DB, Kies MS, Mao L, Weber RS, ElNaggar AK. Genetic and expression analysis of HER-2 and EGFR genes in salivary duct carcinoma: empirical and therapeutic significance. Clin Cancer Res. 2010;16(8):2266-74.

57. Hashimoto K, Yamamoto H, Shiratsuchi H, et al. HER-2/neu gene amplification in carcinoma ex pleomorphic adenoma in relation to progression and prognosis: a chromogenic in situ hybridization study. Histopathology. 2012;60(6B):E131-42.

58. Cho KJ, Lee SS, Lee YS. Proliferating cell nuclear antigen and c-erbB-2 oncoprotein expression in adenoid cystic carcinomas of the salivary glands. Head Neck. 1999;21(5):414-9.

59. Press MF, Pike MC, Hung G, et al. Amplification and overexpression of HER-2/neu in carcinomas of the salivary gland: correlation with poor prognosis. Cancer Res. 1994;54(21): $5675-82$.

60. Hao L, Xiao-lin N, Qi C, Yi-ping Y, Jia-quan L, Yan-ning L. Nerve growth factor and vascular endothelial growth factor: retrospective analysis of 63 patients with salivary adenoid cystic carcinoma. Int J Oral Sci. 2010;2(1):35-44.

61. •• Ivanov SV, Panaccione A, Brown B et al. TrkC signaling is activated in adenoid cystic carcinoma and requires NT-3 to stimulate invasive behavior. Oncogene 2013; 32(32): 3698-3710. In this brilliant study, the authors describe a previously unrecognized pro-survival neurotrophin signaling pathway in AdCC. They explore the expression of the neurotrophin-3 receptor TrkC/NTRK3, neural crest marker SOX10 and other neurologic genes as a new specific molecular biological feature explaining the perineural growth tendency of this tumor. They substantiate the importance of this finding by describing the effect a novel potent Trk inhibitor AZD7451 that blocks TrkC activation.

62. - Ach T, Zeitler K, Schwarz-Furlan S et al. Aberrations of MET are associated with copy number gain of EGFR and loss of PTEN and predict poor outcome in patients with salivary gland cancer. Virchows Arch 2013; 462(1): 65-72. Interesting study investigating hepatocyte growth factor receptor (MET), a known key driver of oncogenic transformation in other tumors, in 266 patients with SGC. The authors see gain but also loss of genomic MET activity being associated with EGFR and PTEN signaling, 
but also with clinicopathological prognostic factors related to aggressive tumor growth, nodal metastasis and worse overall survival. They conclude this may be a target for molecular biological therapies of salivary gland carcinomas in the future.

63. Ettl T, Gosau M, Brockhoff $\mathrm{G}$ et al. Predictors of cervical lymph node metastasis in salivary gland cancer. Head Neck 2013; doi: 10.1002/hed.23332.

64. Zhang CY, Mao L, Li L, et al. Promoter methylation as a common mechanism for inactivating E-cadherin in human salivary gland adenoid cystic carcinoma. Cancer. 2007;110(1):87-95.

65. Sun ZJ, Chen G, Hu X, et al. Activation of PI3 K/Akt/IKKalpha/NF-kappaB signaling pathway is required for the apoptosis-evasion in human salivary adenoid cystic carcinoma: its inhibition by quercetin. Apoptosis. 2010;15(7):850-63 .

66. Hamakawa H, Nakashiro K, Sumida T, et al. Basic evidence of molecular targeted therapy for oral cancer and salivary gland cancer. Head Neck. 2008;30(6):800-9.

67. Frierson HF Jr, El-Naggar AK, Welsh JB, et al. Large scale molecular analysis identifies genes with altered expression in salivary adenoid cystic carcinoma. Am J Pathol. 2002;161(4): 1315-23.

68. Pramoonjago P, Baras AS, Moskaluk CA. Knockdown of Sox4 expression by RNAi induces apoptosis in ACC3 cells. Oncogene. 2006;25(41):5626-39.

69. Ivanov SV, Panaccione A, Nonaka D, et al. Diagnostic SOX10 gene signatures in salivary adenoid cystic and breast basal-like carcinomas. Br J Cancer. 2013;109(2):444-51.

70. Deguchi H, Hamano H, Hayashi Y. c-myc, ras p21 and p53 expression in pleomorphic adenoma and its malignant form of the human salivary glands. Acta Pathol Jpn. 1993;43(7-8):413-22.

71. van Halteren HK, Top B, Mooi WJ, Balm AJ, Rodenhuis S. Association of H-ras mutations with adenocarcinomas of the parotid gland. Int J Cancer. 1994;57(3):362-4.

72. Yoo J, Robinson RA. H-ras gene mutations in salivary gland mucoepidermoid carcinomas. Cancer. 2000;88(3):518-23.

73. Greer RO Jr, Said S, Shroyer KR, Marileila VG, Weed SA. Overexpression of cyclin D1 and cortactin is primarily independent of gene amplification in salivary gland adenoid cystic carcinoma. Oral Oncol. 2007;43(8):735-41.

74. Lee CH, Hung YJ, Lin CY, Hung PH, Hung HW, Shieh YS. Loss of SFRP1 expression is associated with aberrant beta-catenin distribution and tumor progression in mucoepidermoid carcinoma of salivary glands. Ann Surg Oncol. 2010;17(8):2237-46.

75. Ge MH, Chen C, Xu JJ, Ling ZQ. Unfavorable clinical implications for hypermethylation of RUNX3 in patients with salivary gland adenoid cystic carcinoma. Oncol Rep. 2011;26(2):349-57.

76. - Qi C, Shao Y, Li N, Zhang C, Zhao M, Gao F. Prognostic significance of PDCD4 expression in human salivary adenoid cystic carcinoma. Med Oncol 2013; 30(1):491. This is the first study looking at PDCD4 expression in AdCC. The authors found this tumor suppressor gene downregulated in 62 of 96 tumor samples, and this decreased PDCD4 expression paralleled the important prognostic factor UICC stage.

77. Shao C, Tan M, Bishop JA, et al. Suprabasin is hypomethylated and associated with metastasis in salivary adenoid cystic carcinoma. PLoS ONE. 2012;7(11):e48582.

78. Tameno H, Chano T, Ikebuchi K, et al. Prognostic significance of RB1-inducible coiled-coil 1 in salivary gland cancers. Head Neck. 2012;34(5):674-80.

79. Sun J, Luo Y, Tian Z, Gu L, Xia SC, Yu Y. Expression of ERBB3 binding protein 1 (EBP1) in salivary adenoid cystic carcinoma and its clinicopathological relevance. BMC Cancer. 2012;12:499.

80. Adelstein DJ, Koyfman SA, El-Naggar AK, Hanna EY. Biology and management of salivary gland cancers. Semin Radiat Oncol. 2012;22(3):245-53.
81. - Ettl T, Baader K, Stiegler C et al. Loss of PTEN is associated with elevated EGFR and HER2 expression and worse prognosis in salivary gland cancer. Br J Cancer 2012; 106(4):719-26. Again an interesting study from the German group correlating homogeneous genomic PTEN deletion as well as loss of PTEN expression to increased gene copy number and overexpression of EGFR/Her-1 and to amplification and overexpression of Her2 in salivary gland carcinomas. This feature parallels unfavorable prognosis and indicates a possibility of meaningful targeted therapy.

82. Piha-Paul SA, Cohen PR, Kurzrock R. Salivary duct carcinoma: targeting the phosphatidylinositol 3-kinase pathway by blocking mammalian target of rapamycin with temsirolimus. J Clin Oncol. 2011;29(26):e727-30.

83. Declercq J, Van Dijck F, Van Damme B, Van de Ven W. Upregulation of Igf and Wnt signalling associated genes in pleomorphic adenomas of the salivary glands in PLAG1 transgenic mice. Int J Oncol. 2008;32(5):1041-7.

84. El-Naggar AK, Lovell M, Killary AM, Clayman GL, Batsakis JG. A mucoepidermoid carcinoma of minor salivary gland with $\mathrm{t}(11 ; 19)(\mathrm{q} 21 ; \mathrm{p} 13.1)$ as the only karyotypic abnormality. Cancer Genet Cytogenet. 1996;87(1):29-33.

85. Behboudi A, Enlund F, Winnes M, et al. Molecular classification of mucoepidermoid carcinomas-prognostic significance of the MECT1-MAML2 fusion oncogene. Genes Chromosom Cancer. 2006;45(5):470-81.

86. Garcia JJ, Hunt JL, Weinreb I, et al. Fluorescence in situ hybridization for detection of MAML2 rearrangements in oncocytic mucoepidermoid carcinomas: utility as a diagnostic test. Hum Pathol. 2011;42(12):2001-9.

87. Anzick SL, Chen WD, Park Y, et al. Unfavorable prognosis of CRTC1-MAML2 positive mucoepidermoid tumors with CDKN2A deletions. Genes Chromosom Cancer. 2010;49(1): 59-69.

88. Bell D, Roberts D, Karpowicz M, Hanna EY, Weber RS, ElNaggar AK. Clinical significance of Myb protein and downstream target genes in salivary adenoid cystic carcinoma. Cancer Biol Ther. 2011;12(7):569-73.

89. Cruz Perez DE, de Abreu AF, Nobuko NI, de Almeida OP, Kowalski LP. Prognostic factors in head and neck adenoid cystic carcinoma. Oral Oncol. 2006;42(2):139-46.

90. Dodd RL, Slevin NJ. Salivary gland adenoid cystic carcinoma: a review of chemotherapy and molecular therapies. Oral Oncol. 2006;42(8):759-69.

91. Luukkaa H, Klemi P, Leivo I, Vahlberg T, Grenman R. Prognostic significance of Ki-67 and p53 as tumor markers in salivary gland malignancies in Finland: an evaluation of 212 cases. Acta Oncol. 2006;45(6):669-75.

92. Genetzakis M, Gomatos IP, Georgiou AN, et al. BCL-2, p53 and HLA-DR antigen expression in surgically treated parotid cancer patients. Eur Arch Otorhinolaryngol. 2009;266(3):417-24.

93. Franchi A, Gallo O, Bocciolini C, Franchi L, Paglierani M, Santucci M. Reduced E-cadherin expression correlates with unfavorable prognosis in adenoid cystic carcinoma of salivary glands of the oral cavity. Am J Clin Pathol. 1999;111(1):43-50.

94. Zhang CY, Mao L, Li L, et al. Promoter methylation as a common mechanism for inactivating E-cadherin in human salivary gland adenoid cystic carcinoma. Cancer. 2007;110(1): 87-95.

95. Wang YY, Chen WL, Huang ZQ, et al. Expression of the membrane-cytoskeletal linker Ezrin in salivary gland adenoid cystic carcinoma. Oral Surg Oral Med Oral Pathol Oral Radiol Endod. 2011;112(1):96-104.

96. Kim SH, Carey TE, Liebert M, Yoo SJ, Kwon HJ, Kim SY. Characterization of AMC-HN-9, a cell line established from an undifferentiated carcinoma of the parotid gland: expression of 
alpha6beta4 with the absence of BP180 and 230. Acta Otolaryngol. 2000;120(5):660-6.

97. Gurzu S, Krause M, Ember I, et al. Mena, a new available marker in tumors of salivary glands? Eur J Histochem. 2012;56(1):e8.

98. Soave DF, da Oliveira Costa JP, da Silveira GG. CD44/CD24 immunophenotypes on clinicopathologic features of salivary glands malignant neoplasms. Diagn Pathol. 2013;8(1):29.

99. Ben Izhak O, Kaplan-Cohen V, Ilan N, Gan S, Vlodavsky I, Nagler R. Heparanase expression in malignant salivary gland tumors inversely correlates with long-term survival. Neoplasia. 2006;8(10):879-84

100. Yang $X$, Zhang $P$, Ma Q, et al. EMMPRIN silencing inhibits proliferation and perineural invasion of human salivary adenoid cystic carcinoma cells in vitro and in vivo. Cancer Biol Ther. 2012;13(2):85-91.

101. Luukkaa H, Klemi P, Hirsimaki P, et al. Matrix metalloproteinase (MMP)-7 in salivary gland cancer. Acta Oncol. 2010; 49(1):85-90.

102. Piao S, Zhao S, Guo F, et al. Increased expression of CD147 and MMP-9 is correlated with poor prognosis of salivary duct carcinoma. J Cancer Res Clin Oncol. 2012;138(4):627-35.

103. Zhao D, Yang K, Tang XF, Lin NN, Liu JY. Expression of integrin-linked kinase in adenoid cystic carcinoma of salivary glands correlates with epithelial-mesenchymal transition markers and tumor progression. Med Oncol. 2013;30(3):619.

104. •- Jaspers HC, Verbist BM, Schoffelen R et al. Androgen receptor-positive salivary duct carcinoma: a disease entity with promising new treatment options. J Clin Oncol 2011;29(16):473-6. This is a very nice report of the new approach of androgen deprivation therapy for androgen receptor-positive SDC. The authors describe two patients with AR-positive SDC as well as the outcome of a case series involving a total of ten patients treated with androgen deprivation therapy, with an impressive clinical benefit.

105. - Locati LD, Perrone F, Losa M et al. Treatment relevant target immunophenotyping of 139 salivary gland carcinomas (SGCs). Oral Oncol 2009. This is a very informative report analyzing $S G C$ deregulation gene profiles that could become targets for molecular bullets in samples from 139 patients.

106. Wu HM, Ren GX, Wang LZ, Zhang CY, Chen WT, Guo W. Expression of podoplanin in salivary gland adenoid cystic carcinoma and its association with distant metastasis and clinical outcomes. Mol Med Rep. 2012;6(2):271-4.

107. - Melnick M, Sedghizadeh PP, Allen CM, Jaskoll T. Human cytomegalovirus and mucoepidermoid carcinoma of salivary glands: Cell-specific localization of active viral and oncogenic signaling proteins is confirmatory of a causal relationship. Exp Mol Pathol 2011; 92(1):118-25. Remarkable study where the authors find support for their hypothesis that cytomegalovirus $(h C M V)$, which is frequently resident in salivary gland ductal epithelium, would be important to the pathogenesis of $S G$ mucoepidermoid carcinoma: protein markers for active $h C M V$ are present in $97 \%$ of MECs, hCMV-specific proteins (IE1, pp65) are in specific salivary gland cell types, expression positively correlates with severity, and hCMV correlates and colocalizes with an upregulation and activation of the oncogenic signaling pathway COX/AREG/EGFR/ERK.

108. Bell A, Bell D, Weber RS, El-Naggar AK. CpG island methylation profiling in human salivary gland adenoid cystic carcinoma. Cancer. 2011;117(13):2898-909.

109. Bell D, Bell A, Roberts D, Weber RS, El-Naggar AK. Developmental transcription factor EN1-a novel biomarker in human salivary gland adenoid cystic carcinoma. Cancer. 2012;118(5):1288-92.

110. Licitra L, Marchini S, Spinazze S, et al. Cisplatin in advanced salivary gland carcinoma. A phase II study of 25 patients. Cancer. 1991;68(9):1874-7.
111. de Haan LD, De Mulder PH, Vermorken JB, Schornagel JH, Vermey A, Verweij J. Cisplatin-based chemotherapy in advanced adenoid cystic carcinoma of the head and neck. Head Neck. 1992;14(4):273-7.

112. Verweij J, de Mulder PH, de Graeff A, et al. Phase II study on mitoxantrone in adenoid cystic carcinomas of the head and neck. EORTC Head and Neck Cancer Cooperative Group. Ann Oncol. 1996;7(8):867-9.

113. Vermorken JB, Verweij J, de Mulder PH, et al. Epirubicin in patients with advanced or recurrent adenoid cystic carcinoma of the head and neck: a phase II study of the EORTC Head and Neck Cancer Cooperative Group. Ann Oncol. 1993;4(9):785-8.

114. Airoldi M, Pedani F, Succo G, et al. Phase II randomized trial comparing vinorelbine versus vinorelbine plus cisplatin in patients with recurrent salivary gland malignancies. Cancer. 2001;91(3):541-7.

115. Gilbert J, Li Y, Pinto HA, et al. Phase II trial of taxol in salivary gland malignancies (E1394): a trial of the Eastern Cooperative Oncology Group. Head Neck. 2006;28(3):197-204.

116. van Herpen CM, Locati LD, Buter J, et al. Phase II study on gemcitabine in recurrent and/or metastatic adenoid cystic carcinoma of the head and neck (EORTC 24982). Eur J Cancer. 2008;44(17):2542-5.

117. Alberts DS, Manning MR, Coulthard SW, Koopmann CF Jr, Herman TS. Adriamycin/cis-platinum/cyclophosphamide combination chemotherapy for advanced carcinoma of the parotid gland. Cancer. 1981;47(4):645-8.

118. Licitra L, Cavina R, Grandi C, et al. Cisplatin, doxorubicin and cyclophosphamide in advanced salivary gland carcinoma. A phase II trial of 22 patients. Ann Oncol. 1996;7(6):640-2.

119. Debaere D, Vander Poorten V, Nuyts S. Cyclophosphamide, doxorubicin, and cisplatin in advanced salivary gland cancer. B-ENT. 2011;7(1):1-6.

120. Tsukuda M, Kokatsu T, Ito K, Mochimatsu I, Kubota A, Sawaki S. Chemotherapy for recurrent adeno- and adenoidcystic carcinomas in the head and neck. J Cancer Res Clin Oncol. 1993;119(12):756-8.

121. Venook AP, Tseng A Jr, Meyers FJ, et al. Cisplatin, doxorubicin, and 5-fluorouracil chemotherapy for salivary gland malignancies: a pilot study of the Northern California Oncology Group. J Clin Oncol. 1987;5(6):951-5.

122. Ross PJ, Teoh EM, A'Hern RP, et al. Epirubicin, cisplatin and protracted venous infusion 5-Fluorouracil chemotherapy for advanced salivary adenoid cystic carcinoma. Clin Oncol (R Coll Radiol). 2009;21(4):311-4.

123. Dimery IW, Legha SS, Shirinian M, Hong WK. Fluorouracil, doxorubicin, cyclophosphamide, and cisplatin combination chemotherapy in advanced or recurrent salivary gland carcinoma. J Clin Oncol. 1990;8(6):1056-62.

124. Airoldi M, Fornari G, Pedani F, et al. Paclitaxel and carboplatin for recurrent salivary gland malignancies. Anticancer Res. 2000;20(5C):3781-3.

125. Laurie SA, Siu LL, Winquist E, et al. A phase 2 study of platinum and gemcitabine in patients with advanced salivary gland cancer: a trial of the NCIC Clinical Trials Group. Cancer. 2010;116(2):362-8.

126. Lagha A, Chraiet N, Ayadi M, et al. Systemic therapy in the management of metastatic or advanced salivary gland cancers. Oral Oncol. 2012;48(10):948-57.

127. • Laurie SA, Ho AL, Fury MG, Sherman E, Pfister DG. Systemic therapy in the management of metastatic or locally recurrent adenoid cystic carcinoma of the salivary glands: a systematic review. Lancet Oncol 2011;12(8):815-824. This is a superb systematic review summarizing the existing literature on the available treatment options for patients with metatstatic AdCC. 
128. Tanvetyanon T, Qin D, Padhya T, et al. Outcomes of postoperative concurrent chemoradiotherapy for locally advanced major salivary gland carcinoma. Arch Otolaryngol Head Neck Surg. 2009;135(7):687-92.

129. Pederson AW, Salama JK, Haraf DJ, et al. Adjuvant chemoradiotherapy for locoregionally advanced and high-risk salivary gland malignancies. Head Neck Oncol. 2011;3:31.

130. Lin CH, Yen RF, Jeng YM, Tzen CY, Hsu C, Hong RL. Unexpected rapid progression of metastatic adenoid cystic carcinoma during treatment with imatinib mesylate. Head Neck. 2005;27(12): 1022-7.

131. Ghosal N, Mais K, Shenjere P, et al. Phase II study of cisplatin and imatinib in advanced salivary adenoid cystic carcinoma. $\mathrm{Br}$ J Oral Maxillofac Surg. 2011;49(7):510-5.

132. Glisson BS, Blumenschein G, Francisco M, Erasmus J, Zinner $\mathrm{R}$, Kies M. Phase II trial of gefitinib in patients with incurable salivary gland cancer. ASCO Annual Meeting Proceedings 23. 2005.

133. Chau NG, Hotte SJ, Chen EX, et al. A phase II study of sunitinib in recurrent and/or metastatic adenoid cystic carcinoma (ACC) of the salivary glands: current progress and challenges in evaluating molecularly targeted agents in ACC. Ann Oncol. 2012; 23(6):1562-70.

134. Glisson B, Colevas AD, Haddad R, et al. HER2 expression in salivary gland carcinomas: dependence on histological subtype. Clin Cancer Res. 2004;10(3):944-6.

135. - Limaye SA, Posner MR, Krane JF et al. Trastuzumab for the treatment of salivary duct carcinoma. Oncologist 2013;18(3):294-300. This is a nice study documenting the usefulness of testing for the HER2/neu gene amplification in SDC in view of a combination of trastuzumab and paclitaxel/carboplatin; in both the adjuvant setting (5 of 8 patients remained disease free more than 2 years from completion of therapy) and palliative setting 5 of 5 patients with metastatic disease responded, and one patient achieved a complete response persisting for 52 months.

136. Rugo HS, Herbst RS, Liu G, et al. Phase I trial of the oral antiangiogenesis agent AG-013736 in patients with advanced solid tumors: pharmacokinetic and clinical results. J Clin Oncol. 2005;23(24):5474-83. 